\title{
Control strategies for reactive batch distillation
}

\author{
Eva Sørensen and Sigurd Skogestad* \\ Department of Chemical Engineering, University of Trondheim-NTH, N-7034 Trondheim, \\ Norway
}

\begin{abstract}
A batch reactor may be combined directly with a distillation column by distilling off the light component product in order to increase the reactor temperature or to improve the product yield of an equilibrium reaction. The same amount of the light product should be removed as the amount being formed by the reaction at any time. A linearized model has been developed which describes the process behaviour satisfactorily for control analysis purposes. The controllability of a combined batch reactor/batch distillation column is found to depend strongly on the operating conditions and on the time during the run. In general, controlling only the reactor temperature (one-point bottom control) is difficult since the set-point has to be specified below a maximum value in order to avoid break-through of an intermediate component in the distillate. This maximum value may be difficult to know a priori. For the example considered in this study, control of both reactor temperature and distillate composition (two-point control) is also found to be difficult due to large interactions in the column. As with one-point bottom control, the reactor temperature has to be specified below a maximum value. However, energy can be saved since the heat duty can be decreased with time. Controlling the temperature on a tray in the column (one-point column control) is found to give good performance for the given process with no loss of reactant and a high reactor temperature, although no direct control of the reactor temperature is obtained.
\end{abstract}

Keywords: reactive batch distillation; dynamic behaviour; controllability

Batch distillation is used in the chemical industry for the production of small amounts of products with high added value and for processes where flexibility is needed, for example, when there are large variations in the feed composition or when production demand is varying. A batch reactor can be combined with a distillation column as shown in Figure 1. The objective is to increase the reaction temperature and to improve the product yield of equilibrium reactions in the reactor by distilling off one or more of the products, thereby driving the equilibrium towards the products.

Most often the control objective when considering batch processes is either to minimize the batch time or to maximize the product quality or yield. Most of the papers published on batch distillation focus on finding optimal reflux ratio policies. However, sometimes the control objective is simply to obtain the same conditions in each batch. This was the case for the specific industrial application which was the starting point for our interest in this problem and which is to be presented later.

Few authors have considered the operation of batch distillation with chemical reaction, although these processes are inherently difficult to control. The analysis of such systems in terms of controllability has so far only been considered by Sørensen and Skogestad ${ }^{1,2}$. Roat et

*Author to whom correspondence should be addressed. E-mail: skoge@kjemi.unit.no

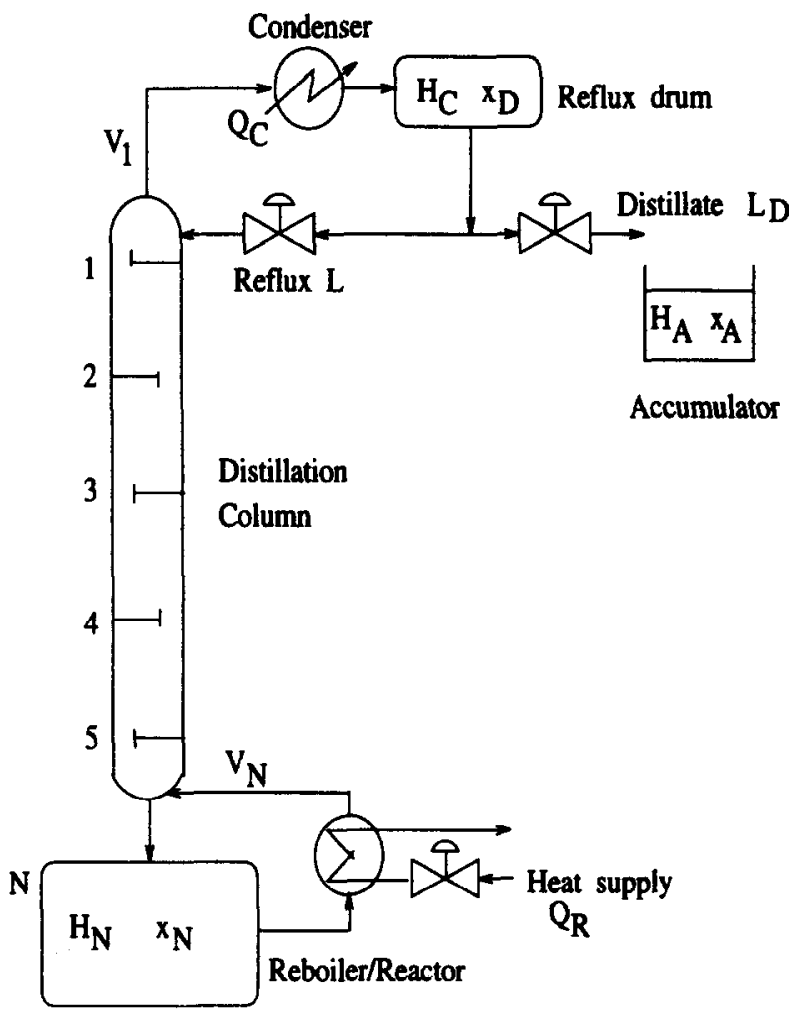

Figure 1 Batch distillation column/reactor

$a l .^{3}$ have developed a methodology for designing control schemes for continuous reactive distillation columns 
based on interaction measures together with rigorous dynamic simulation. However, no details about their model were given.

Modelling and simulation of reactive batch distillation have been investigated by Cuille and Reklaitis ${ }^{4}$, Reuter $e t$ al. ${ }^{5}$ and Albet et al. ${ }^{6}$. Cuille and Reklaitis ${ }^{4}$ developed a model and solution strategies for the simulation of a staged batch distillation column with chemical reaction in the liquid phase. Reuter et al. ${ }^{5}$ incorporated the simulation of a PI-controller in their model of a batch column with reaction only in the reboiler. The controller was used to control the top tray temperature using the distillate flow as manipulated variable. They stated that their model could be used for the investigation of control structure with the aid of relative gain array (RGA) analysis but no details were given. Albet et al. ${ }^{6}$ presented a method for the development of operational policies based on simulation strategies for multicomponent batch distillation applied to reactive and non-reactive systems.

Egly et $a l^{7.8}$ considered optimization and operation of a batch distillation column accompanied by a chemical rcaction in the reboiler. Egly et al. ${ }^{7}$ presented a method for the optimization of batch distillation based upon models which included the non-ideal behaviour of multicomponent mixtures and the kinetics of chemical reactions. The column operation was optimized by using the reflux ratio as a control variable. Feeding one of the reactants during the reaction was also considered. In a later paper, they also considered control of the column based upon temperature measurements from different parts of the column. The optimal reflux ratio policy was achieved by adjusting the distillate flow using a nonlinear control system. However, no details were given about either the column/reactor or the control system.

The purpose of this paper is to give an understanding of the dynamic behaviour of reactive batch distillation and to show how this process differs from batch distillation without reaction. Also we investigate the possible difficulties in controlling a reactive batch distillation process and give some alternative control strategies based on an industrial example.

First, an industrial process, consisting of a batch reactor with a rectifying column on top, is presented. In this process the reaction is limited to the reactor/reboiler. Based on a staged equilibrium model of this process, we present special features of reactive batch distillation. We show how a linearized model of the process can be used to describe the behaviour in different operating points, and based on this linear model we present a simple controllability analysis based on step responses. Several control strategies are presented. We consider two-point control, where both the top and the bottom part are controlled, as well as one-point control, when only one part of the column/reactor is controlled. An RGA analysis is used for the investigation of control structures in two-point control.

\section{Process example}

In this study we have developed a dynamic model for a combined batch reactor/batch distillation process consisting of a total mass balance, the mass balances for each component, the energy balance, linear tray hydraulics and Raoult's law for the vapour-liquid equilibrium. A staged equilibrium model is used for the distillation column and the condenser holdup is assumed to be perfectly controlled. The dynamic model is given in the Appendix. It was solved and linearized using the program SPEEDUP.

The basis for the study is an industrial equilibrium esterification reaction of the type:

$$
\xi_{1} \mathrm{R}_{1}+\xi_{2} \mathrm{R}_{2}+\xi_{3} \mathrm{R}_{3} \rightleftharpoons \mathrm{P}(\mathrm{s})+\mathrm{W}
$$

where $R_{1}$ is a dibasic aromatic acid (therephthalic acid with $T_{\mathrm{b}}=767^{\circ} \mathrm{C}$ ), $\mathrm{R}_{2}$ and $\mathrm{R}_{3}$ are glycols (1,2-propanediol with $T_{\mathrm{b}}=188^{\circ} \mathrm{C}$ and 1,6 -hexanediol with $T_{\mathrm{b}}=243^{\circ} \mathrm{C}$ ), P is the solid polymer product (here given as the monomer block) and $\mathrm{W}$ is the side-product (water with $T_{\mathrm{b}}=$ $100^{\circ} \mathrm{C}$ ). The overall reaction rate is described by the following rate equation:

$$
r_{\mathrm{N}}=r_{\mathrm{R}_{1}}=k_{1} c_{\mathrm{R}_{1}}\left(c_{\mathrm{R}_{2}}+c_{\mathrm{R}_{3}}\right)-k_{2} c_{\mathrm{w}}
$$

where

$$
k_{i}=k_{0 i} \exp \left(-\frac{E_{i}}{R_{\mathrm{g}}}\left(\frac{1}{T_{\mathrm{N}}}-\frac{1}{T_{0}}\right)\right)
$$

The activation energy for the reverse reaction is the same as for the forward reaction, i.e. $E_{1}=E_{2}$. The frequency factor for the reverse reaction $k_{0,2}$ is one fourth that of the forward reaction $k_{0,1}$. However, the reverse reaction is usually negligible as the concentration of $\mathrm{W}$ in the reactor $c_{\mathrm{W}}$ will in most cases be very small (typically about $0.005 \mathrm{kmol} \mathrm{m}^{-3}$ comparcd to about $4.7 \mathrm{kmol} \mathrm{m}^{-3}$ for $R_{1}$ ) since the water is constantly removed by distillation. The reverse reaction will only have some influence at the very end when most of the reactants have been used up and

\begin{tabular}{|c|c|}
\hline Column & $\begin{array}{l}\text { Reboiler }+ \text { five trays }+ \text { total condenser }+ \\
\text { accumulator }\end{array}$ \\
\hline Reaction & $1.0 \mathrm{R}_{1}+0.7 \mathrm{R}_{2}+0.3 \mathrm{R}_{3} \rightarrow \mathrm{P}(\mathrm{s})+2.0 \mathrm{~W}$ \\
\hline Activation energies & $\begin{array}{l}E_{1}=E_{2}=18 \mathrm{kcal} / \mathrm{mol} \\
=7.5 \times 10^{4} \mathrm{~kJ} \mathrm{kmol}-1\end{array}$ \\
\hline Frequency factors & $\begin{array}{l}k_{0.1}=0.06 \mathrm{~m}^{3} \mathrm{~h}^{-1} \text { and } k_{0.2} \\
=0.015 \mathrm{~m}^{6} \mathrm{kmol}^{-1} \mathrm{~h}^{-1}\end{array}$ \\
\hline $\begin{array}{l}\text { Reference temperature } \\
\text { for } k_{i}\end{array}$ & $T_{0}=500.0 \mathrm{~K}$ \\
\hline $\begin{array}{l}\text { Pressure in column/ } \\
\text { reactor }\end{array}$ & $1 \mathrm{~atm}$ \\
\hline $\begin{array}{l}\text { Maximum heat input, } \\
Q_{\text {R.max }}\end{array}$ & $0.85 \times 10^{6} \mathrm{~kJ} \mathrm{~h}^{-1}=236.1 \mathrm{~kW}$ \\
\hline $\begin{array}{l}\text { Hydraulic time } \\
\text { constant, } \tau\end{array}$ & $0.0018 \mathrm{~h}=6.5 \mathrm{~s}$ \\
\hline Condenser holdup, $H_{\mathrm{C}}$ & $1.7 \mathrm{kmol}$ \\
\hline $\begin{array}{l}\text { Initial holdup on the } \\
\text { trays, } H_{i}^{0}\end{array}$ & $0.1 \mathrm{kmol}$ \\
\hline Initial feed & $\begin{array}{l}\mathbf{R}_{1}: 10.40 \mathrm{kmol} \text { (acid) } \\
\mathbf{R}_{2}: 7.28 \mathrm{kmol} \text { (alcohol) } \\
\mathbf{R}_{3}: 3.12 \mathrm{kmol} \text { (alcohol) } \\
\mathbf{P}: 0.00 \mathrm{kmol} \text { (ester) } \\
\mathbf{W}: 2.20 \mathrm{kmol} \text { (water) }\end{array}$ \\
\hline
\end{tabular}
also $c_{\mathrm{R}_{1}}, c_{\mathrm{R}_{2}}$ and $c_{\mathrm{R}_{1}}$ are small. A summary of the process data is given in Table 1. The physical properties data for 


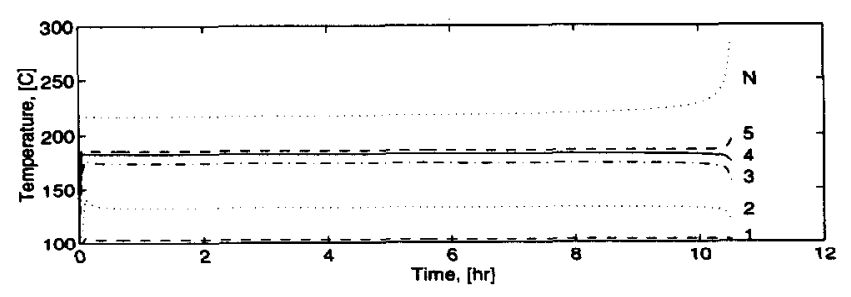

Figure 2 Temperature profile with existing control strategy (one-point top control) without disturbances

the components $\left(P_{j i}^{\mathrm{vap}}, h_{j}^{\mathrm{L}}, h_{j}^{\mathrm{v}}\right.$ and $\left.\rho_{i}\right)$ were taken from Daubert and Danner'.

In the industrial unit the amount of reactant $R_{2}$ in the feed was $20 \%$ higher than necessary to yield complete conversion of the reaction. This was done to account for the possible loss of the reactant in the distillate with the existing operating procedurc. In this study no excess of $\mathbf{R}_{2}$ was used.

This process has been studied earlier ${ }^{1,2,10}$. Compared to the process model used previously ${ }^{1,2}$, in this study the number of stages in the column is reduced from six to five and the excess of $R_{2}$ is no longer included. Furthermore the model is extended to include energy balances and a temperature- and concentration-dependent reaction rate (see Appendix). The optimization and on-line operation of the process using one-point column control were studied elsewhere ${ }^{10}$.

The existing operating procedure was to use one-point top control; the temperature at the top of the column $T_{1}$ was kept constant at about $103^{\circ} \mathrm{C}$ using the reflux flow as manipulated variable. Simulations with the dynamic model in the Appendix gives a distillate composition of 0.004 (about $2 \mathrm{wt} \%$ ) of the reactant $\mathrm{R}_{2}$ and thereby a loss of this component (about $1 \%$ in total). Due to disturbances such as varying pressure, this loss was often higher in practice. The vapour flow was maximized by using maximum constant heating of the reactor $Q_{\mathrm{R} \text {,max }}$ and the condenser level was controlled by the distillate flow $L_{\mathrm{D}}$. The simulated temperature profile with this control strategy for the ideal case with no disturbances is given in Figure 2. The reactor temperature $T_{\mathrm{N}}$ is almost constant at the beginning but increases slightly as the reaction proceeded. There is a sharp increase in temperature at the end of the reaction when the light reactant $R_{2}$ is almost used up. The conditions on trays 4 and 5 are practically equal because the column has more stages than are needed for the desired separation. The conversion at the end point of $10.5 \mathrm{~h}$ is only 0.957 due to the loss of $R_{2}$.

With the existing control scheme there is no direct control of the reactor temperature $T_{\mathrm{N}}$ and, more severely, there is a varying loss of the reactant $R_{2}$. This leads to a varying quality of the product $P(s)$ between batches.

For this equilibrium reaction, combining the reactor with the distillation column has two effects:

- Increase the reactor temperature by removing the light component $\mathrm{W}$. This will also increase the rate constants and thereby the reaction rate.

- Drive the equilibrium reaction towards the products by removing the side-product $W$.
For this example, the rate of the reverse reaction is in most cases very low due to the low concentration of $W$ in the reactor and the main effect will therefore be the increase in reactor temperature.

In operating the process one of the main objectives is to keep the reactor temperature as high as possible in order to reduce the reaction time. One way of achieving this is to run the process under pressure, but this was not possible for the industrial process studied in this example. However, the reactor temperature must not exceed $240^{\circ} \mathrm{C}$ since this might lead to decomposition of the polymer product $\mathbf{P}$.

\section{Understanding reactive batch distillation}

The conventional operating policies for normal batch distillation columns are:

- constant distillate composition $x_{\mathrm{D}}$ (or temperature $\left.T_{1}\right)$,

- constant reflux ratio $R$,

- time varying reflux ratio $R(t)$.

The constant distillate composition procedure is normally implemented using feedback control with either reflux flow or distillate flow as manipulated variable. The reflux ratio procedures are open loop, that is, predefined values are used without feedback from the process.

As long as the set-point for the controlled variable $x_{\mathrm{D}}$ or the manipulated variable $R$ is high enough compared to the heat input $Q_{\mathrm{R}}$ the separation in the column will be satisfactory. Overspecifying the set-point, e.g. setting the reflux ratio to a higher value than necessary, will only result in a slightly longer batch time but the products being distilled will be purer than specified.

In the case of reactive batch distillation, where a reaction is taking place either only in the reboiler/reactor or in the whole column, some of the components will be removed and some will be formed in addition to what is removed or fed as part of the separation. The obvious question is then: can the same operating policies be used as for normal batch distillation? The answer is 'yes' for the constant distillate composition policy, but 'no' for the open-loop reflux policies, and in this section we will explain why.

\section{Constant reflux policy}

The temperature profile for the reactor when the process is operated according to the constant reflux ratio procedure with $R=0.92$ is given in Figure 3. Simulations with and without disturbances are given. The disturbance is assumed to be in the reboiler heat duty $Q_{\mathrm{R}}$ $( \pm 18 \%)$. The temperature profile for the case with disturbances (solid line) deviates significantly from the ideal one without disturbances (dotted line). It should be noted that the loss of reactant $R_{2}$ is only $3.7 \times 10^{-5}$ and $9.1 \times 10^{-5} \mathrm{kmol}$ for the undisturbed and disturbed case respectively. However, the reboiler temperature deviates 

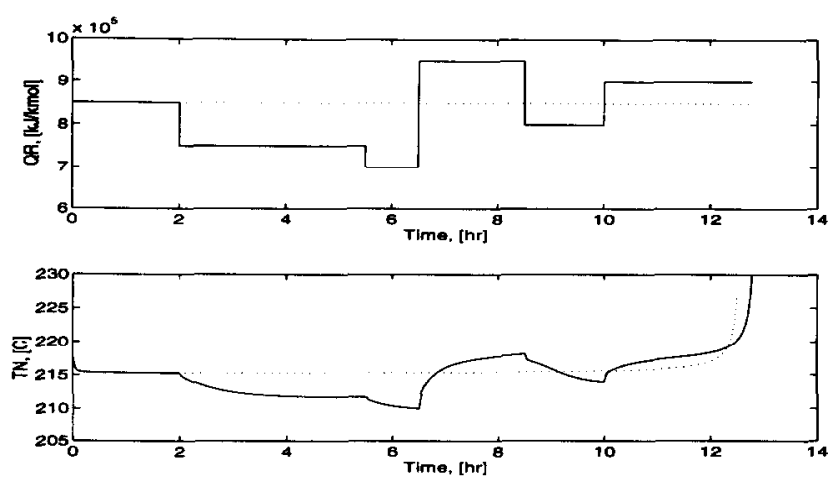

Figure 3 Top, disturbances in heat input; bottom, reactor temperature profile with constant reflux ratio $R=0.92$ with (-) and without ( $(\ldots)$ disturbance in heat input

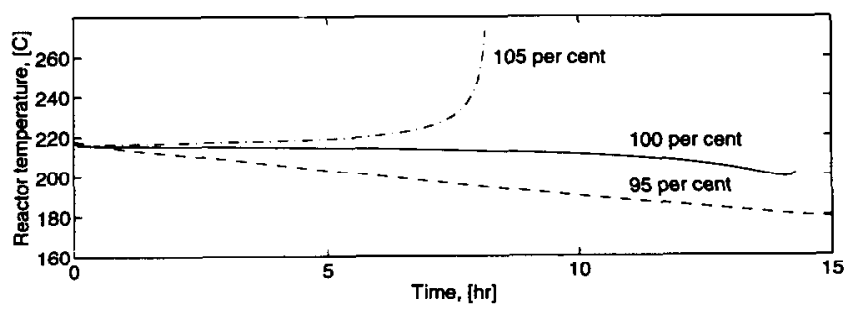

Figure 4 Reactor temperature when the removal of light side-product $\mathrm{W}$ is $95 \%, 100 \%$ and $105 \%$ of the amount formed at any time

up to $6^{\circ} \mathrm{C}$ from the undisturbed one, which will result in a varying quality of the product $P$ between batches.

An open-loop operating procedure (such as reflux ratio procedures) is therefore, in the case of reactive batch distillation, not good enough, even though the separation in the column section might be satisfactory (little reactant $\mathrm{R}_{2}$ was lost in either case in Figure 3). Because of the reaction in the reactor we need some sort of feedback control with the reactor/column conditions in order to reduce the effect of possible disturbances on the reaction.

\section{Effect of product flow}

To understand the above results we consider the effect of the distillate (product) flow. Ideally, the same amount of the light product should be removed in the separation as the amount being formed by the reaction at any time. If less is removed in the distillate, too much light product will be left in the column and the ovcrall reaction rate will decrease due to the reduced temperature. If the distillate flow is too high, all the light product formed will be removed but in addition also some of the light reactants. Some of the reactants are thereby lost and the conversion will be reduced. Also in some cases these reactants must be removed from the distillate later.

This is shown in Figure 4 for the reversible reaction considered in this study. On the plot the reaction is run until $99 \%$ conversion or until less than $1 \times 10^{-4} \mathrm{kmol} \mathbf{R}_{2}$ is left in the reactor. In Table 2 the loss of $R_{2}$, the conversion, the final batch time, the amount of product and the total energy consumption for each of the cases shown in Figure 4 are given. It can be seen that when the distillate flow is too high ( $105 \%$ removal) not only the light product $\mathrm{W}$ will be removed but also some of the reactant $R_{2}$. The reactor temperature increases as the reactant is removed and the reaction stops when all the light reactant is either reacted or removed. This loss of one of the reactants will not only result in a reduced amount of polymer product $P$ but also in a polymer which will have a different molecular structure. When the distillate flow is too slow (95\% removal) and not all of the light product $\mathrm{W}$ formed in the reactor is removed, the reactor temperature decreases and the reaction becomes very slow. After $15 \mathrm{~h}$ the conversion is still only $63 \%$. For the case when the exact amount is removed $(100 \%$ removal) the temperature is decreasing during the batch. This is due to the amount of side-product $W$ in the reboiler initially which is added to dissolve the heavier components. Since only the amount formed by the reaction is removed, the mole fraction of water in the reboiler will increase as the reaction proceeds and the reactants are used up, and the temperature will therefore decrease. In fact, removing some of the initial water together with what is formed will speed up the reaction by increasing the temperature, but care must be taken so that no reactant $R_{2}$ is lost (not shown).

For the reaction considered here the temperature dependency of the reaction rate is the dominant effect. If the reaction is considered to be irreversible $\left(r_{\mathrm{N}}=k_{1} c_{\mathrm{R}_{1}}\right.$ $\left.\left(c_{R_{2}}+c_{R_{3}}\right)\right)$ the same results as presented in Figure 4 are obtained (not shown).

\section{Controllability analysis}

In this section we describe some important features considering the dynamic behaviour of reactive batch distillation using the process example. A linear model is developed for this purpose. Measurements, manipulated variables and disturbances are defined and the effects of operating point and disturbances on the measurements are discussed.

\section{Linear model}

In order to investigate the controllability of a process using available tools, a linear model is needed. Based on the non-linear model described in the Appendix a linear model can be developed by linearizing the equation system at a given operating point. For continuous processes normally only one operating point is considered: that of the steady state conditions. The linear model is then found by linearizing around this operating point and will be valid for small deviations from the steady state. When considering batch processes there is no such steady state; the conditions in the reactor or column are changing with time and the model is linearized along a trajectory. A linearized model of the process can be described by the following equations:

$$
\begin{aligned}
& \mathrm{d} \mathbf{x} / \mathrm{d} t=A \mathbf{x}+B \mathbf{u}+E \mathbf{d} \\
& \mathbf{y}=C \mathbf{x}+D \mathbf{u}+F \mathbf{d}
\end{aligned}
$$


Table 2 Results for different product flows

\begin{tabular}{lcccrr}
\hline $\begin{array}{l}\text { Removal as \% } \\
\text { of formation }\end{array}$ & $\begin{array}{c}\text { Loss of reactant } \\
\mathbf{R}_{2}(\mathrm{kmol})\end{array}$ & $\begin{array}{c}\text { Conversion } \\
\text { of } \mathbf{R}_{1}\end{array}$ & $\begin{array}{c}\text { Final batch } \\
\text { time }(\mathrm{h})\end{array}$ & $\begin{array}{c}\text { Product P, kmol } \\
\text { (monomer block) }\end{array}$ & $\begin{array}{r}\text { Energy } \\
\text { consumption (kJ) }\end{array}$ \\
\hline 105.00 & 1.091 & 0.764 & 8.157 & 7.946 & $6.9 \times 10^{6}$ \\
100.00 & $2.2 \times 10^{-5}$ & 0.990 & 14.303 & 10.296 & $12.2 \times 10^{6}$ \\
95.00 & $3.8 \times 10^{-6}$ & 0.990 & 328.041 & 10.296 & $278.8 \times 10^{6}$ \\
\hline
\end{tabular}

where

$$
\begin{aligned}
& \mathbf{x}=[\text { all states }]^{\mathrm{T}} \\
& \mathbf{y}=\left[\Delta T_{\mathrm{N}}, \Delta x_{\mathrm{D}, 2}, \Delta T_{\mathrm{c}}, \Delta T_{1}, \Delta T_{2}, \Delta T_{3}, \Delta T_{4}, \Delta T_{5}\right]^{\mathrm{T}} \\
& \mathbf{u}=\left[\Delta L_{\mathrm{D}}, \Delta L,\left(\Delta Q_{\mathrm{R}}\right)\right]^{\mathrm{T}} \\
& \mathbf{d}=\left[\Delta P_{\mathrm{N}},\left(\Delta Q_{\mathrm{R}}\right), \Delta \xi_{2}, \Delta E_{1}, \Delta k_{0,1}, \Delta k_{0,2}\right]
\end{aligned}
$$

Laplace transformation yields:

$$
\mathbf{y}(s)=G(s) \mathbf{u}(s)+G_{d}(s) \mathbf{d}(s)
$$

All variables represent deviations from the 'natural drift' along the trajectory with the flows and disturbances constant. It is the deviation from the natural drift which is important for control since this is the only thing the control system can affect. However, since this is a batch process which is never at a steady-state, the way we have reached the linearization point is also of importance since this will affect the states in the model (even when at a given time the values of the disturbances and outputs are identical). In this section we have used the trajectories given by $100 \%$ removal as presented earlier.

In defining the linear model we have assumed that the temperature in the reboiler $T_{\mathrm{N}}$ can be measured in addition to the amount of reactant $R_{2}$ in the distillate flow $x_{\mathrm{D}, 2}$. These are the two variables we are mostly interested in controlling. In addition we also assume that the temperature in the condenser and on all the trays can be measured. The manipulated variables are the distillate flow $L_{\mathrm{D}}$, the reflux flow $L$ and in some cases the heat input to the reboiler $Q_{R}$. If the heat input is assumed to be set as it will be when one-point control is used (normally at its maximum value to reduce the batch time) it will be a possible disturbance. Other main disturbances are the pressure in the reactor and the reaction parameters (stoichiometric coefficient, activation energy and frequency factors).

In Figure 5 the linear and non-linear model are compared for a $10 \%$ step in reflux flow $L$ at $t=6 \mathrm{~h}$. It can be seen from the figure that the linear model describes the responses well up until $\approx 0.1 \mathrm{~h}$ or $6 \mathrm{~min}$. The linear model can therefore be used for control analysis purposes since in that case only the initial responses are of interest.

\section{Effect of operating point}

In the previous section it was shown how the system changes with different product flows. It is obvious that the conditions in the column/reactor change when the
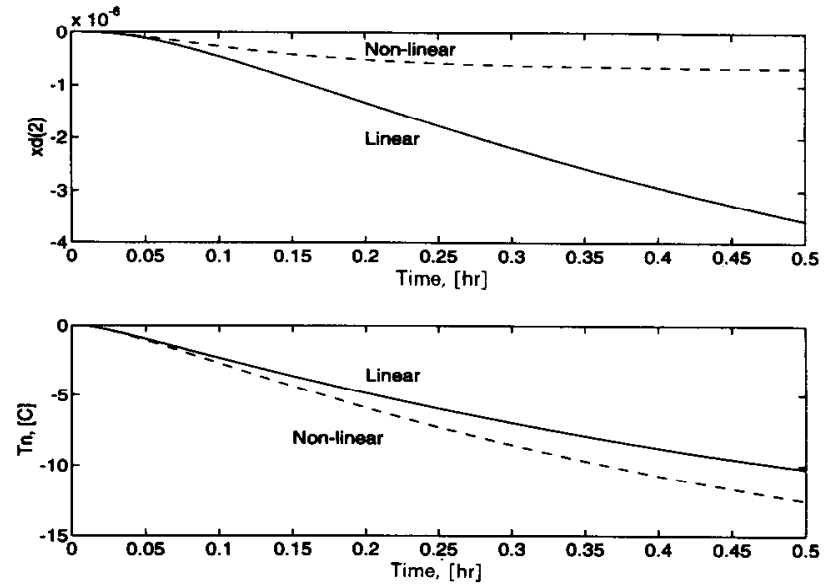

Figure $510 \%$ step in reflux flow $L$ : effect on distillate composition $x_{\mathrm{D}, 2}$ and reactor temperature $T_{\mathrm{N}}$ for linear and non-linear model (at $t=6 \mathrm{~h}$ with $100 \%$ removal of $W$ )
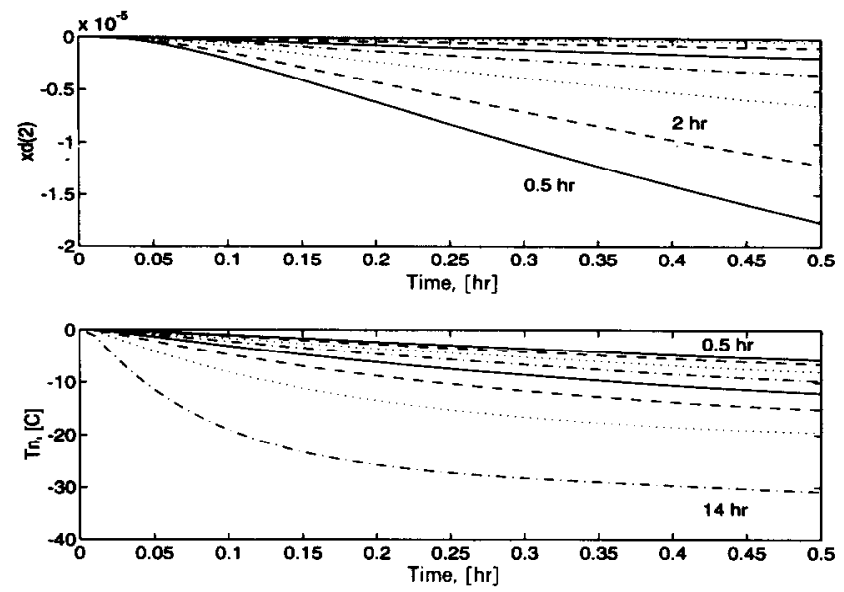

Figure $65 \%$ step in reflux flow $L$ for linear model: effect on distillate composition and reactor temperature for different operating points

operating parameters, such as product flow, change. However, the conditions also change during the run.

In Figure 6 linear responses for a step in reflux for the case with $100 \%$ removal are given at different operating points for the distillate composition and the reboiler temperature $(t=0.5,2,4,6,8,10,12$ and $14 \mathrm{~h})$. It can be seen that the effect on temperature increases with time and especially towards the end of the batch. The responses in distillate composition vary considerably, with the largest response at the beginning of the batch. However, the responses are similar but differ in magnitude if plotted on log-scale (not shown). The difference in responses is due to the changing conditions in the column/ reactor with a light/heavy front in the column section which is lowered with time, thus giving the reduced responses in distillate composition and the increased responses in reactor temperature. 

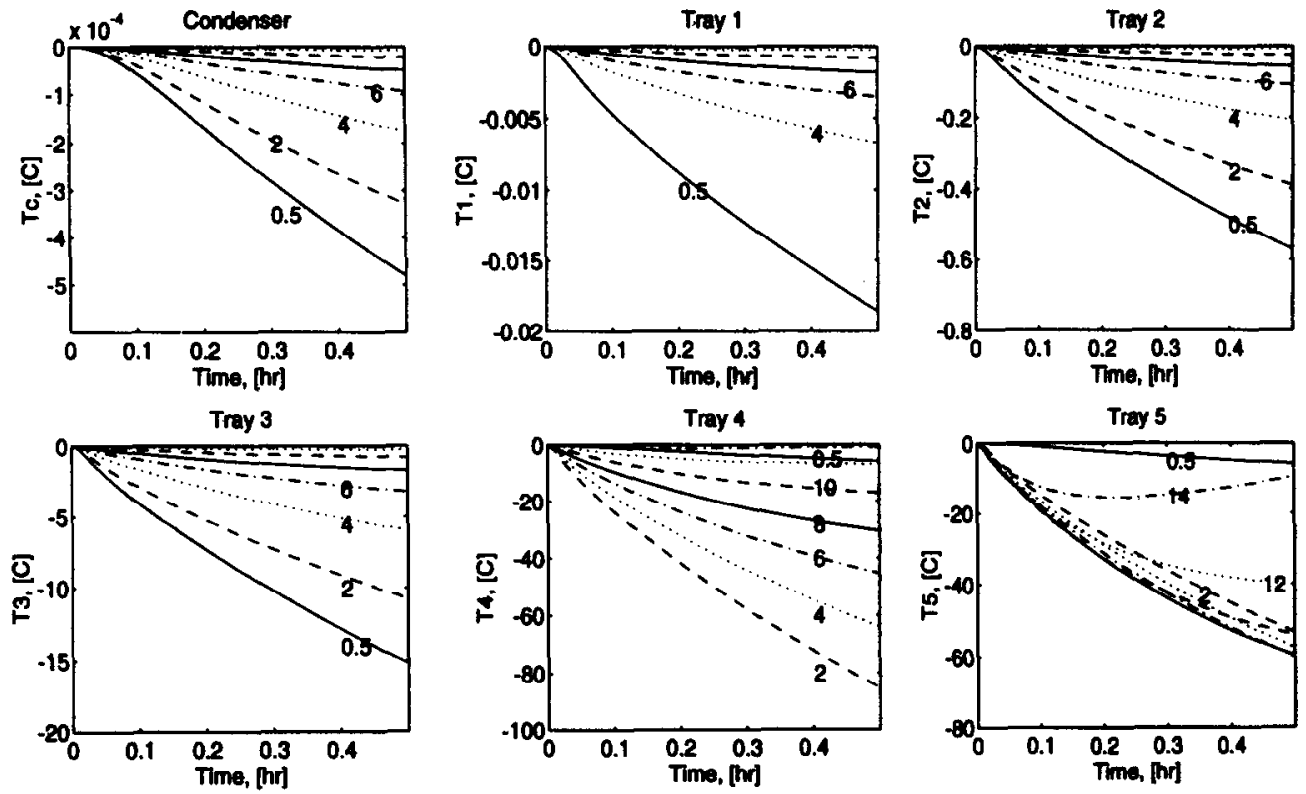

Figure $75 \%$ step in reflux flow $L$ for linear model: effect on condenser and tray temperatures for different operating points. (Note that the scaling differs)

In Figure 7 the responses for all tray temperatures at different operating points for the same step in reflux flow are given. In can be seen that the effect by the step is largest for trays 4 and 5 and almost negligible for the top of the column. (Remember that the existing operating procedure was to control the temperature on tray 1 using the reflux flow as manipulated variable, which is seen to be difficult due to the very small responses). The responses on tray 5 are more or less equal except at the beginning and end of the batch. For all the other trays the responses decrease constantly with time.

Reducing the non-linearity in distillate composition. An interesting feature in Figure 6 is that the responses in distillate composition to step changes have a similar initial shape if plotted on a log-scale. This is actually a general property for distillation". The inherent nonlinearities in this variable can therefore be reduced by using a log transformation on the distillate composition $x_{\mathrm{D}}$ :

$$
X_{\mathrm{D}, \text { light }}=-\ln \left(1-x_{\mathrm{D} \text {,light }}\right)
$$

which in deviation variables becomes:

$$
\Delta X_{\mathrm{D} \text {.light }}=\frac{\Delta x_{\mathrm{D}, \text { light }}}{1-x_{\mathrm{D}, \text { light }}^{*}} \text { and } \Delta X_{\mathrm{D}, \text { heavy }}=\frac{\Delta x_{\mathrm{D} \text {,heavy }}}{x^{*} \text {, heavy }}
$$

The responses for the distillate composition $X_{\mathrm{D}, \text { heavy }}=$ $X_{\mathrm{D} .2}$ after the transformation are given in Figure 8 . These

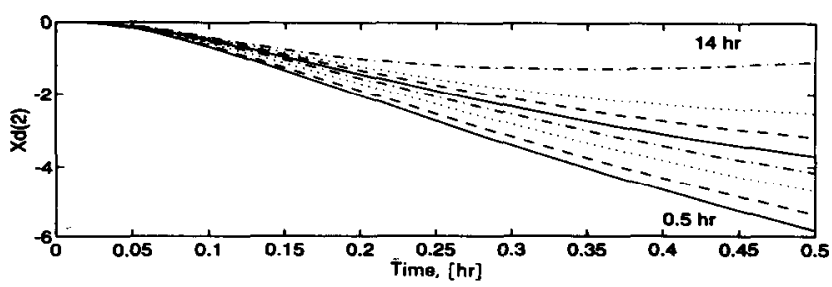

Figure $85 \%$ step in reflux flow $L$ for linear model: effect on the logarithmic distillate composition for different operating points initial responses, which are of primary importance for control, are very similar for the various operating points, and the non-linearity is thereby reduced compared to Figure 6. From Figure 6 there is no obvious transformation that can be suggested to deal with the non-linear effect for the reactor temperature.

\section{Effect of disturbances}

We have identified the main disturbances to be the reboiler heat duty $Q_{\mathrm{R}}$ in those cases where it is not used as a manipulated variable (one-point top or column control), the pressure in the reactor $P_{\mathrm{N}}$ and the reaction parameters; the stoichiometric coefficients for the alcohols $\left(\xi_{2}\right.$ and $\left.\xi_{3}=-1+\xi_{2}\right)$, the activation energy for the reaction $\left(E_{1}=E_{2}\right)$ and the frequency factors for the forward and reverse reaction $\left(k_{0,1}\right.$ and $\left.k_{0,2}\right)$. The selected reaction parameters are used to represent uncertainty in the reaction mechanism.

Linear step responses in reactor temperature and distillate composition by $10 \%$ steps in the disturbances are given in Figure 9 for operating point $t=6 \mathrm{~h}$ with $100 \%$ removal of side-product $W$. It can be seen from the plots that for this operating point the reboiler heat duty $Q_{\mathrm{R}}$ is the largest disturbance with the largest expected effect. Also the pressure $P_{\mathrm{N}}$ and the frequency factor for the forward reaction $k_{0,1}$ have some effect.

\section{Important considerations for control}

In the previous sections we have shown the importance of feedback control for reactive batch distillation and explained why conventional batch distillation operating policies cannot be used in the reactive case. Also we have identified the following problems in operating a reactive batch distillation process: 

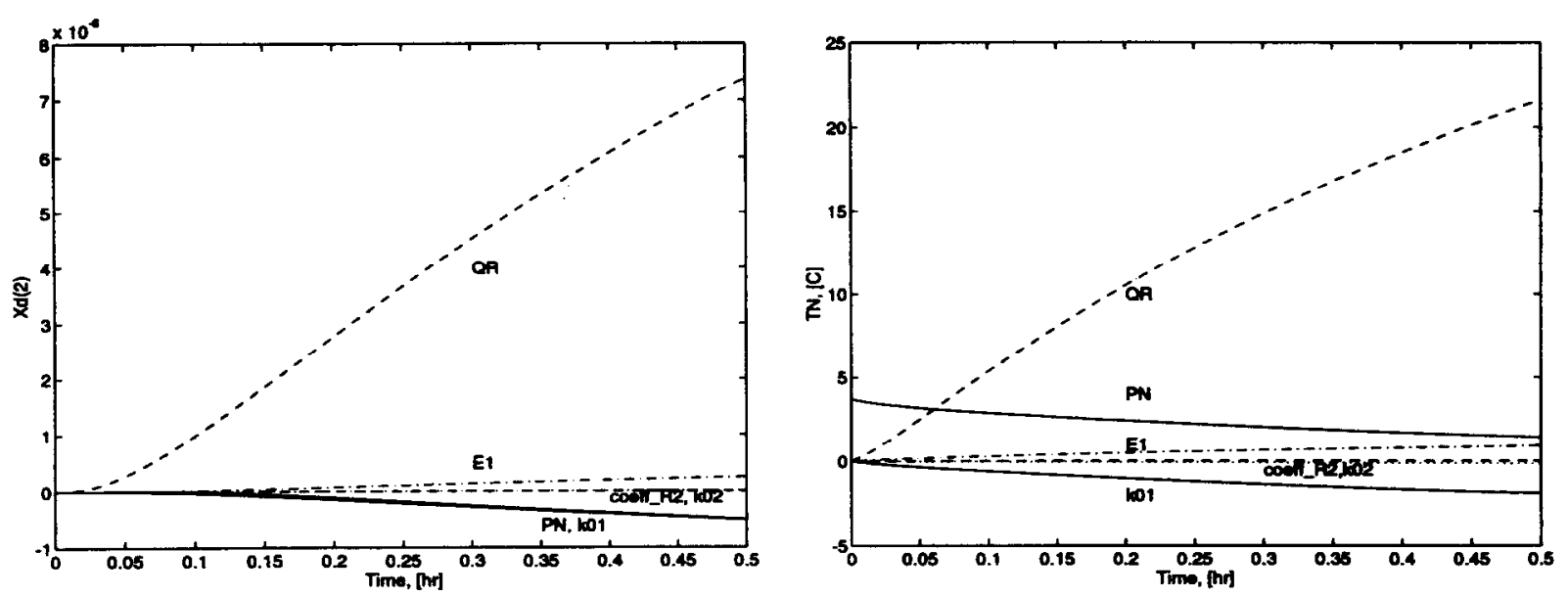

Figure 9 Effect on distillate composition and reactor temperature by $10 \%$ steps in disturbances ( $t=6 \mathrm{~h}$ with $100 \%$ removal)

Table 3 Control parameters used in the simulations

\begin{tabular}{lll}
\hline Bottom control & $K_{\mathrm{p}}=3.0$ and $\tau_{\mathrm{1}}=0.1 \mathrm{~h}$ & $\left(T_{\mathrm{N}} \rightarrow L\right)$ \\
Two-point control & $K_{\mathrm{p}}=-2.15$ and $\tau_{\mathrm{1}}=0.1 \mathrm{~h}$ & $\left(X_{\mathrm{D}, 2} \rightarrow L\right)$ \\
& $K_{\mathrm{p}}=-0.12$ and $\tau_{\mathrm{1}}=0.1 \mathrm{~h}$ & $\left(T_{\mathrm{N}} \rightarrow Q_{\mathrm{R}}\right)$ \\
Column control & $K_{\mathrm{p}}=0.25$ and $\tau_{\mathrm{1}}=0.1 \mathrm{~h}$ & $\left(T_{5} \rightarrow L\right)$ \\
\hline
\end{tabular}

- The same amount of side-product being formed should be removed at any time.

- The system's response to changes varies with time as the conditions in the column/reactor change.

- The trays in the column have different and varying sensitivity to changes.

- The responses are generally non-linear.

These factors must be taken into account when deciding the control strategy.

\section{Control strategies}

The varying loss of reactant $\mathbf{R}_{2}$ in the distillate and the lack of direct control of the reactor temperature were the major problems with the existing operating practice using one-point top control. In the control part of this study the following alternative control strategies are considered:

- one-point bottom control (controlling the reactor temperature directly),

- two-point control (controlling both the distillate composition and the reactor temperature),

- one-point column control (controlling the temperature on a tray in the column).

The control parameters for the PI-controllers used in the simulations are given in Table 3. All controllers were tuned such that the closed-loop gain (using the linearized model at $t=6 \mathrm{~h}$ with $100 \%$ removal) was one at frequency $60 \mathrm{rad} \mathrm{h}^{-1}$, giving a response time of $1 \mathrm{~min}$. However, for two-point control the $X_{\mathrm{D}, 2}-L$ loop had to be detuned to a response time of 3 min to reduce the interactions in the column. Note that the transformed variable $X_{\mathrm{D}, 2}$ was used instead of $x_{\mathrm{D}, 2}$ for two-point control.

\section{One-point bottom control}

The objective with one-point bottom control is to keep the reactor temperature constant at the highest possible temperature as this will maximize the rate of reaction for a temperature dependent reaction. The reflux flow $L$ is used as manipulated variable and the heat input to the reactor is kept at its maximum value $\left(Q_{\mathrm{R}}=Q_{\mathrm{R} \text {,max }}=\right.$ $0.85 \times 10^{6} \mathrm{~kJ} \mathrm{kmol}^{-1}$. Consider the following procedures:

$$
\begin{array}{ll}
\text { I } & T_{N}^{\text {set }}=210^{\circ} \mathrm{C} \\
\text { II } & T_{N}^{\text {set }}=215^{\circ} \mathrm{C} \\
\text { III } & T_{N}^{\text {set }}=220^{\circ} \mathrm{C}
\end{array}
$$

The temperature profiles for each procedure are given in Figure 10. In Table 4 the loss of $R_{2}$, the conversion, the final batch time, the amount of product and the total energy consumption for each of the cases shown in Figure 10 are given.

For operating procedures I and II the conditions are more or less constant with time, whereas procedure III
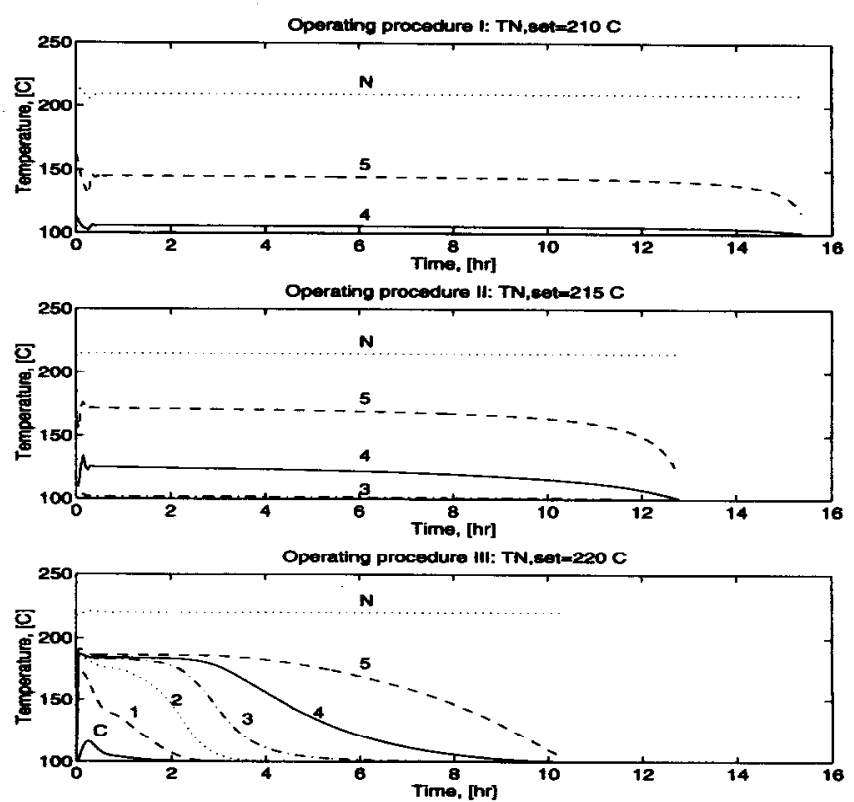

Figure 10 One-point bottom control. Temperature profiles for different operating procedures 
Table 4 Results for one-point bottom control with different set points for the reactor temperatures

\begin{tabular}{lccccc}
\hline $\begin{array}{c}\text { Operating } \\
\text { procedure }\end{array}$ & $\begin{array}{c}\text { Set-point reactor } \\
\text { temperature }\left({ }^{\circ} \mathrm{C}\right)\end{array}$ & $\begin{array}{c}\text { Loss of reactant } \\
\mathbf{R}_{2}(\mathbf{k m o l})\end{array}$ & $\begin{array}{c}\text { Conversion } \\
\text { of } \mathbf{R}_{1}\end{array}$ & $\begin{array}{c}\text { Final batch } \\
\text { time (h) }\end{array}$ & $\begin{array}{c}\text { Product P (kmol) } \\
(\text { monomer block) }\end{array}$ \\
\hline I & 210.0 & $4.3 \times 10^{-6}$ & 0.990 & 15.351 & 10.296 \\
II & 215.0 & $3.0 \times 10^{-5}$ & 0.990 & 12.768 & $13.048 \times 10^{6}$ \\
III & 220.0 & 0.749 & 0.897 & 10.313 & 10.296 \\
\hline
\end{tabular}

has a changing temperature profile with large variations at the beginning of the run but more or less stabilizing midway through. For operating procedure I the front between light and heavy component is low in the column, more light component than necessary is held back and the reaction rate decreases. For operating procedure II the front between light and heavy component is higher in the column and the reaction rate is therefore increased. For operating procedure III the set-point for the reactor temperature is too high and there is a loss of reactant $R_{2}$ during the first couple of hours of the run. This is the same effect as described earlier; if the reactor temperature is too low and too little side product is removed the reaction becomes slow and the conversion decreases, whereas if it is too high and too much is removed the conversion is reduced due to the loss of reactant.

There is in other words a maximum set-point for the reactor temperature in order to maximize the reaction rate but at the same time avoid loss of the reactant $R_{2}$. This maximum value will depend on the relative amounts of the reactants in the feed, on the reaction mechanism and on the disturbances in the system. This is illustrated in Figure 11, which shows how the mole fraction of $\mathrm{R}_{2}$ in the distillate $x_{D, 2}$ changes when the set-point for the temperature controller in the reactor is increased from $T_{\mathrm{N}}^{\mathrm{set}}=216.5^{\circ} \mathrm{C}$ to $T_{\mathrm{N}}^{\mathrm{set}}=217.0^{\circ} \mathrm{C}$. An increase of $0.5^{\circ} \mathrm{C}$ causes the mole fraction of reactant $R_{2}$ to increase by a factor of 25 . However, the loss of reactant is only temporary and $X_{\mathrm{D}, 2}$ is reduced to an acceptable level after about $\mathrm{I} \mathrm{h}$. The breakthrough is caused by the fact that when the specified temperature is above a certain maximum value where most of the light component $W$ is removed, a further increase is only possible by removing the light reactant $R_{2}$. If the set-point temperature is specified below the maximum value, in this case $\approx 216.0^{\circ} \mathrm{C}$, good control of the system $\left(T_{\mathrm{N}} \approx T_{\mathrm{N}, \text { set }}\right.$ and $\left.x_{\mathrm{D}, 2}<1 \times 10^{-5}\right)$ is achieved. The system can, however, become unstable at the end of the batch depending on the choice of control parameters in the PI controller.

Another alternative for raising the reaction temperature, and thereby the reaction rate for a temperature dependent reaction, is to let the set-point follow a given

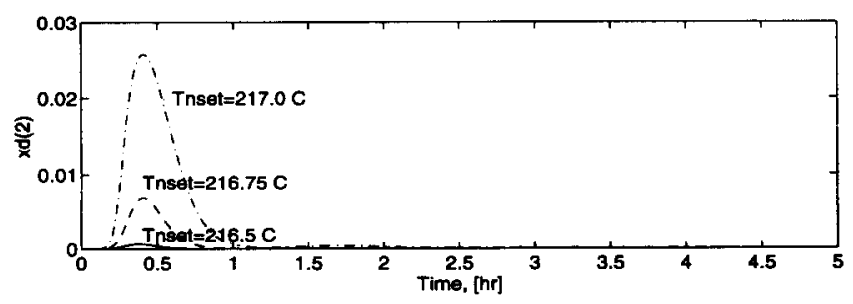

Figure 11 One-point bottom control. Heavy component $R_{2}$ in distillate at different $T_{\mathrm{N}}^{\text {set }}$ for the first $5 \mathrm{~h}$ of the batch trajectory, e.g. a linear increase with time. Again, the maximum reactor temperature to avoid breakthrough will limit the possible increase, and breakthrough is inevitable if it is specified too high (not shown).

\section{Two-point control}

By using two-point control it may be possible to control both the top and the bottom part of the distillation column by implementing two single control loops in the system. In this way energy consumption can be reduced since it will no longer be necessary to keep the reboiler heat duty at its maximum value. In the case of the esterification process, it is desirable to control not only the reactor temperature $T_{\mathrm{N}}$ but also the composition of the distillate $x_{D, 2}$, i.e. the loss of reactant $R_{2}$.

Two different control configurations are considered for the batch column:

$L V$-configuration Controlling the condenser level $H_{\mathrm{C}}$ using the distillate flow $L_{\mathrm{D}}$ leaving the reflux flow $L$ and the reboiler heat duty $Q_{\mathrm{R}}$ to control the distillate composition $X_{\mathrm{D}}$ and the reactor temperature $T_{\mathrm{N}}$ :

$$
\begin{aligned}
& H_{\mathrm{C}} \leftrightarrow L_{\mathrm{D}} \\
& X_{\mathrm{D}, 2}, T_{\mathrm{N}} \leftrightarrow L, Q_{\mathrm{R}}
\end{aligned}
$$

$D V$-configuration Controlling the condenser level $H_{\mathrm{C}}$ using the reflux flow $L$ leaving the distillate flow $L_{\mathrm{D}}$ and the reboiler heat duty $Q_{\mathrm{R}}$ to control the distillate composition $X_{\mathrm{D}}$ and the reactor temperature $T_{\mathrm{N}}$ :

$$
\begin{aligned}
& H_{\mathrm{C}} \leftrightarrow L \\
& X_{\mathrm{D}, 2}, T_{\mathrm{N}} \leftrightarrow L_{\mathrm{D}}, Q_{\mathrm{R}}
\end{aligned}
$$

Note that in both cases the logarithmic distillate composition $X_{\mathrm{D} .2}$ is used.

Analysis of two-point model. Open-loop step responses for both configurations are given in Figures 12 and 13. (The term 'open-loop' should here be put in quotes because we are not talking about an uncontrolled column, but assume that the condenser level is perfectly controlled $\left(H_{\mathrm{C}} \leftrightarrow L_{\mathrm{D}}\right.$ or $\left.H_{\mathrm{C}} \leftrightarrow L\right)$ and we consider the effect of the remaining independent variables on the distillate composition and reactor temperature.) From Figure 12 it can be seen that for the LV-configuration the responses to the chosen steps in $L$ and $Q_{R}$ are similar but opposite in direction. For the DV-configuration the responses by a step in $L_{\mathrm{D}}$ are similar to the step in $L$ for the LV-configuration but in the opposite direction. How- 

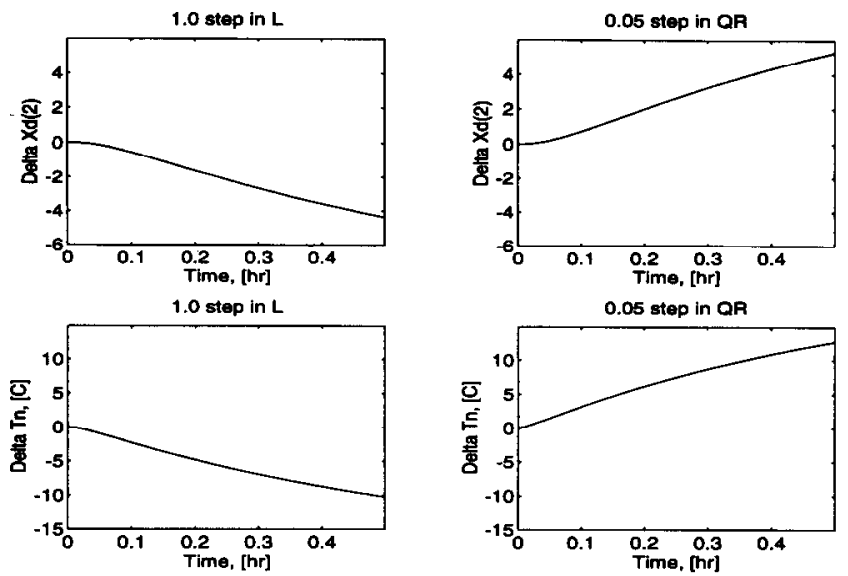

Figure 12 Linear open-loop step responses for LV-configuration $(t=6 \mathrm{~h}$ for $100 \%$ removal of $\mathrm{W})$
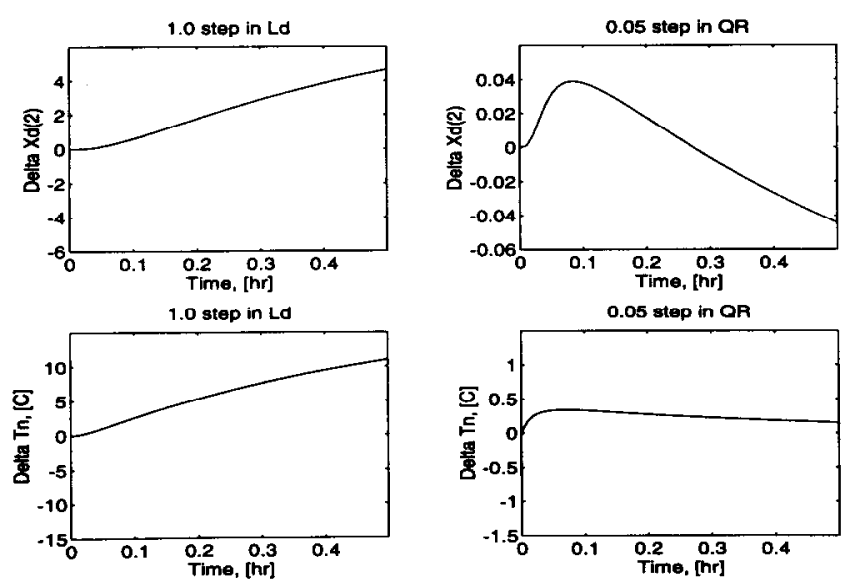

Figure 13 Linear open-loop step responses for DV-configuration $(t=6 \mathrm{~h}$ for $100 \%$ removal of $\mathrm{W})$. Note that the $y$-axis scaling is 100 and 10 times smaller for changes in $Q_{\mathbf{R}}$ compared to the LV-configuration

ever, the responses to a step in $Q_{R}$ are very small and also there is an inverse response in $X_{n, 2}$. This is a general property for distillation ${ }^{12}$.

In a distillation column there are large interactions between the top and the bottom part of the column; a change in the conditions in one end will lead to a change in the other end as well. Because of these interactions a distillation column can be difficult or almost impossible to control. The interactions in a system can be analysed by various tools ${ }^{13}$ including the $\mathrm{RGA}$, or relative gain array. Systems with no interactions will have a RGA value of 1 . The larger the deviation from 1 , the larger the interaction and the more difficult the process is to control. Pairing control loops on steady-state RGA values less than 0 should be avoided.

The magnitude of the 1,1-element of the RGA for both the LV- and DV-configuration is given as a function of frequency in Figure 14. From the figure it can be seen that for the LV-configuration the RGA is very high at low frequencies (when the system is approaching a steady state). This shows that the interaction reduces the effect of the control input $\left(L, Q_{\mathrm{R}}\right)$ and makes control more difficult. RGA for DV is generally lower at all frequen-
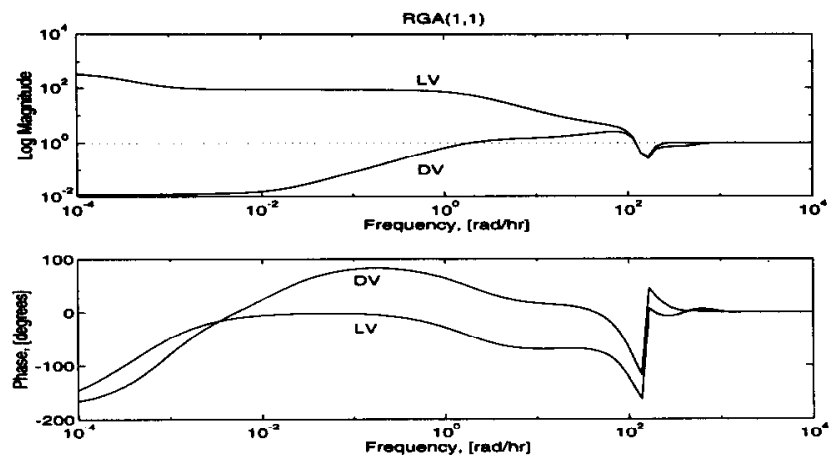

Figure 14 RGA for LV- and DV-configuration for linear model $(t=6$ $h$ for $100 \%$ removal of $W$ )

cies. This difference between the configurations is the same as one would observe in a continuous distillation column.

However, the control characteristics from the RGAplot for the LV-configuration are not quite as bad as it may seem. For control the steady-state values are generally of little interest (particularly in a batch process since the process will never reach such a state), and the region of interest is around the system's closed-loop bandwidth (response to changes), which is in the frequency range around $60 \mathrm{rad} \mathrm{h}^{-1}$ (response time about $1 \mathrm{~min}$ ). We note that the RGA is closer to 1 here and that the difference between the two configurations is much smaller.

From the high-frequency RGA, which is close to 1 , we find that for decentralized control, the loop pairing should always be to use the reboiler heat duty to control the reactor temperature and either the reflux flow or the distillate flow to control the distillate composition or the loss of reactant $\mathbf{R}_{2}$. This is in agreement with physical intuition.

$$
\begin{aligned}
& T_{\mathrm{N}} \leftrightarrow Q_{\mathrm{R}} \\
& X_{\mathrm{D}, 2} \leftrightarrow L, L_{\mathrm{D}} \\
& H_{\mathrm{C}} \leftrightarrow L_{\mathrm{D}}, L
\end{aligned}
$$

Non-linear simulation of two-point model. Closed-loop simulations confirm that two-point control may be used if fast feedback control is possible. However, as in the case for one-point bottom control, we still have the problem of specifying a reasonable set-point for the bottom temperature to avoid breakthrough of reactant $R_{2}$ in the distillate. An example of two-point control of the process using the LV-configuration is given in Figure 15 and Table 5 with the following set-points for the controllers: $T_{\mathrm{N}}^{\text {set }}=215^{\circ} \mathrm{C}$ and $x_{\mathrm{D}, 2}=2.5 \times 10^{-6}$. (Note that we control the transformed distillate composition $X_{\mathrm{D}, 2}$ instead of $x_{\mathrm{D}, 2}$ in order to reduce the non-linearity in the model.) It can be seen that only a minor breakthrough of reactant occurs during the run. Both the distillate composition $x_{\mathrm{D}, 2}$ and the reactor temperature $T_{\mathrm{N}}$ are kept approximately at their set-points through most of the batch but deviate towards the end. It should be noted how the heat duty decreases with time, which shows that energy can be saved using two-point control (compare with procedure II in Table 4 when $Q_{\mathrm{R}}$ is fixed at $0.85 \times 10^{6} \mathrm{~kJ} \mathrm{kmol}^{-1}$ ). 

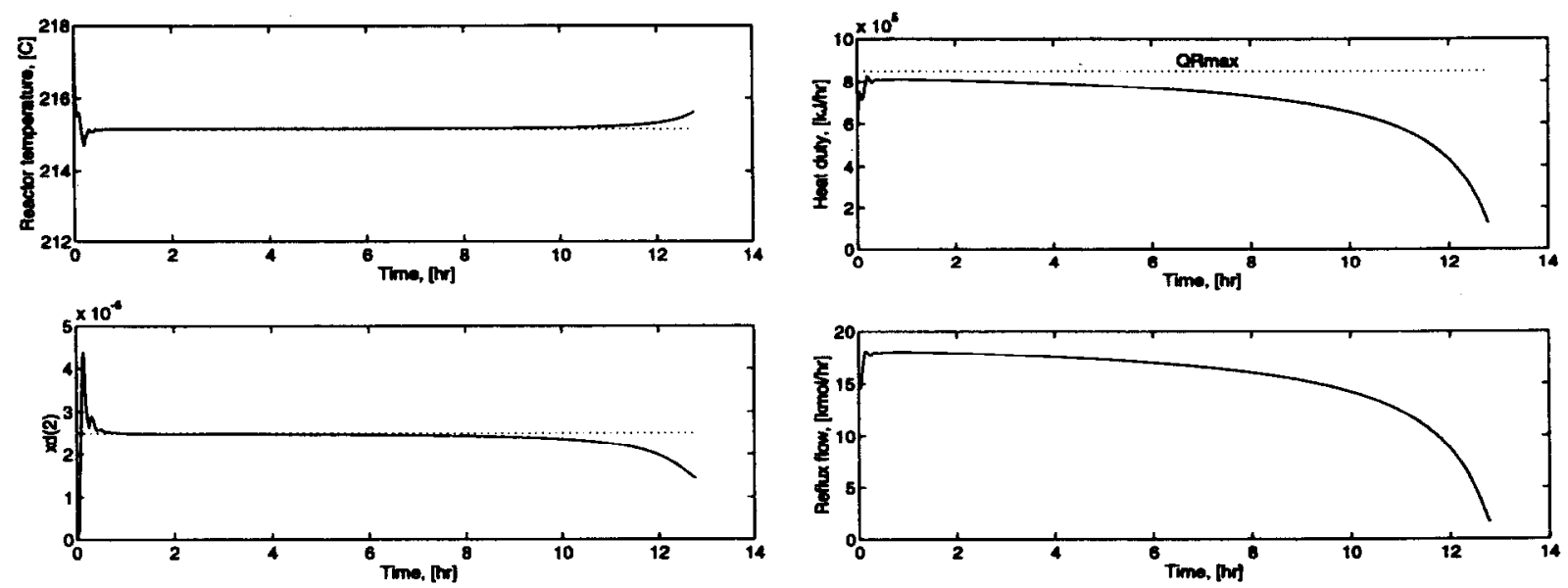

Figure 15 Iwo-point control. Reactor temperature $\left(y_{1}\right)$, distillate composition $\left(y_{2}\right)$, heat input $\left(u_{1}\right)$ and reflux flow $\left(u_{2}\right)$ for $L V$-configuration with setpoints $T_{\mathrm{N}}^{\mathrm{set}}=215^{\circ} \mathrm{C}$ and $x_{\mathrm{D}, 2}=2.5 \times 10^{-6}$

Table 5 Results for two-point control

\begin{tabular}{lccccc}
\hline $\begin{array}{l}\text { Set point reactor } \\
\text { temperature }\left({ }^{\circ} \mathrm{C}\right)\end{array}$ & $\begin{array}{c}\text { Set point } \\
\text { distillate } \\
\text { composition }\end{array}$ & $\begin{array}{c}\text { Loss of reactant } \\
\mathbf{R}_{2}(\mathrm{kmol})\end{array}$ & $\begin{array}{c}\text { Conversion } \\
\text { of } \mathbf{R}_{1}\end{array}$ & $\begin{array}{c}\text { Final batch } \\
\text { time }(\mathrm{h})\end{array}$ & $\begin{array}{c}\text { Product } \mathbf{P}(\mathrm{kmol}) \\
(\text { monomer block) }\end{array}$ \\
\hline 215.0 & $2.5 \times 10^{-6}$ & $4.9 \times 10^{-5}$ & 0.990 & 12.788 & 10.296 \\
\hline
\end{tabular}

To achieve tight control of both ends of the column at the same time is difficult not only due to the interactions in the column (RGA $\approx 5$ at frequency $60 \mathrm{rad} \mathrm{h}^{-1}$ ). Another problem is that the set points for the two loops cannot be specified independently. If the reactor temperature is specified too high, the control system will not be able to maintain the specified purity in the top and will become unstable (not shown). This is due to constraints in $Q_{\mathrm{R} \text {,Ilax }}$ 'Decoupling' the column sections by introducing more trays in the column will reduce the interaction problem.

\section{One-point column control}

With the existing operating practice the temperature at the top of the column was controlled. The set-point was $103^{\circ} \mathrm{C}$ which gave a composition of $0.4 \%$ of reactant $R_{2}$ in the distillate. By lowering the set-point to e.g. $100.1^{\circ} \mathrm{C}$ the distillate would be purer, but the column would become very sensitive to measurement noise, and this system would not work in practice.

One alternative is to measure the composition $x_{\mathrm{D}}$ and use this for feedback as in two-point control in the previous section. However, implementing an analyser (or possibly an estimator based on the temperature profile) is costly and often unreliable. A simpler alternative is to place the temperature measurement further down in the column since this measurement will be less sensitive to noise. In this investigation the temperature on tray 5 , the tray above the reactor, is chosen as the new measurement to be used instead of the one on the top tray. This is because the effect of changes in the manipulated variable $L$ is large and most consistent here (see Figure 7).

The reboiler heat duty is kept fixed at its maximum value $\left(Q_{\mathrm{R}, \max }=0.85 \times 10^{6} \mathrm{~kJ} \mathrm{~h}^{-1}\right)$. With this control configuration $\left(T_{5} \leftrightarrow L\right)$ there is no direct control of the

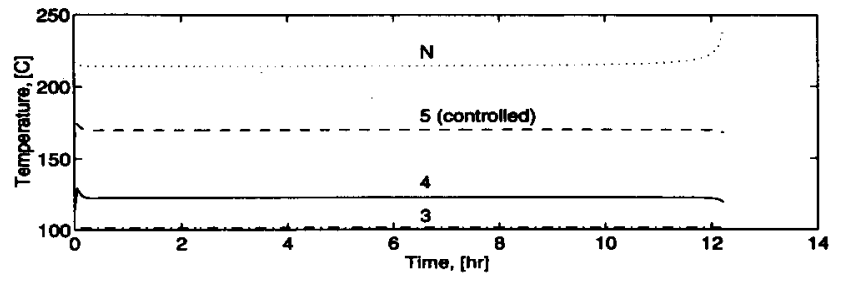

Figure 16 One-point column control. Temperature profile with $T_{5}^{\text {set }}=$ $170^{\circ} \mathrm{C}$

reactor temperature. However, with an appropriate choice of set-point $T_{5}^{\text {set }}$ loss of reactant $\mathrm{R}_{2}$ can easily be avoided and one of the main causes of the operability problems is thereby eliminated.

The temperature profile for one-point column control with set-point $T_{5}^{\text {set }}=170^{\circ} \mathrm{C}$ is shown in Figure 16 and the loss of rcactant $\mathrm{R}_{2}$, the conversion, the final batch time, the amount of product and the total energy consumption are given in Table 6.

The conditions are 'stable' (i.e. no breakthrough of reactant $R_{2}$ ) throughout the batch. The reactor temperature increases towards the end but reaches the maximum reactor temperature before complete conversion. This can be avoided by adding a small excess of reactant $\mathbf{R}_{\mathbf{2}}$ initially to account for the fact that some of this reactant will be located on the trays in the column and will therefore not be accessible for the reaction. Note that this control procedure with $Q_{\mathrm{R}}$ fixed at its maximum will yield the highest possible reactor temperature. This may be important in some cases when the reaction is slow.

\section{Comparison of control strategies}

In this section three alternative control strategies have been presented: 
Table 6 Results for one-point column control

\begin{tabular}{lccccc}
\hline $\begin{array}{c}\text { Set point- } \\
\text { temperature }\left({ }^{\circ} \mathrm{C}\right)\end{array}$ & $\begin{array}{c}\text { Loss of reactant } \\
\mathrm{R}_{2}(\mathrm{kmol})\end{array}$ & $\begin{array}{c}\text { Conversion } \\
\text { of } \mathbf{R}_{\mathbf{l}}\end{array}$ & $\begin{array}{c}\text { Final batch } \\
\text { time }(\mathrm{h})\end{array}$ & $\begin{array}{c}\text { Product } \mathbf{P}(\mathrm{kmol}) \\
\text { (monomer block) }\end{array}$ & $\begin{array}{c}\text { Energy } \\
\text { consumption }(\mathrm{kJ})\end{array}$ \\
\hline 170.0 & $3.6 \times 10^{-5}$ & 0.978 & 12.222 & 10.171 & $10.389 \times 10^{6}$ \\
\hline
\end{tabular}
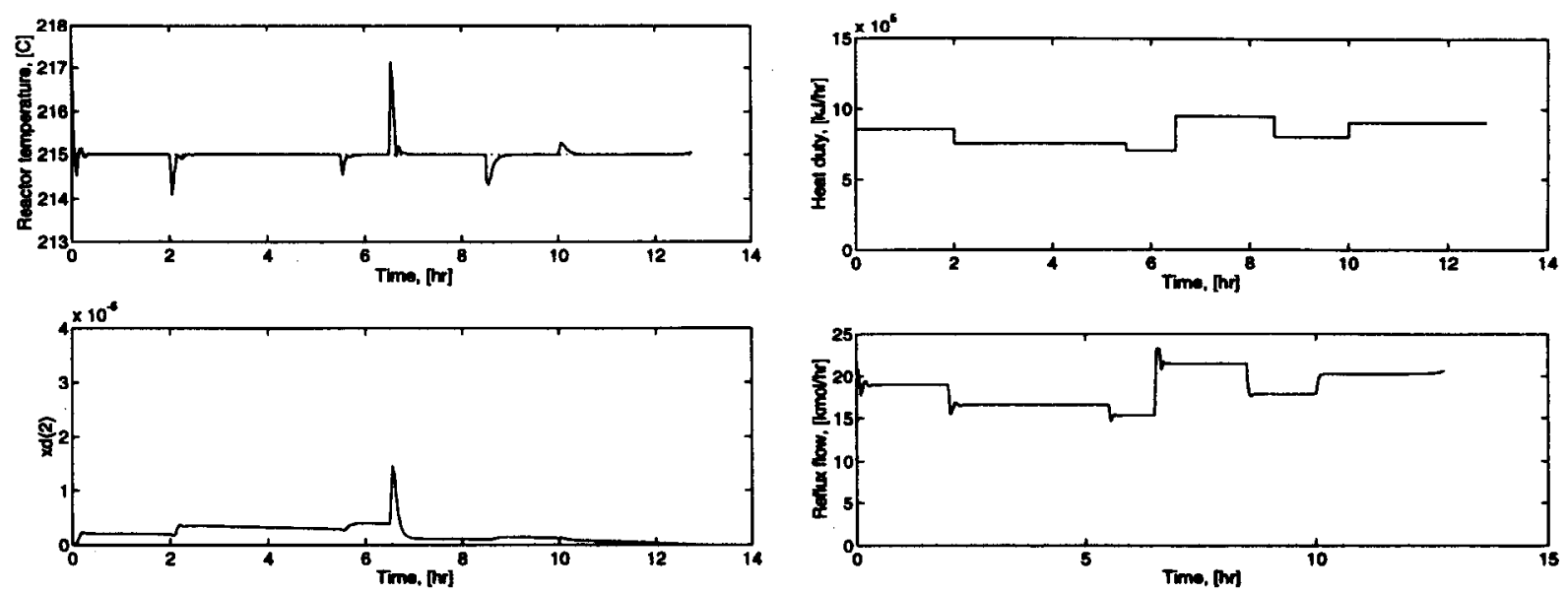

Figure 17 Onc-point bottom control with disturbances in $Q_{R}$. Reactor temperature, distillate composition, heat input and reflux flow with set-point $T_{\mathrm{N}}^{\mathrm{set}}=215^{\circ} \mathrm{C}$. (Dotted line: set-point)
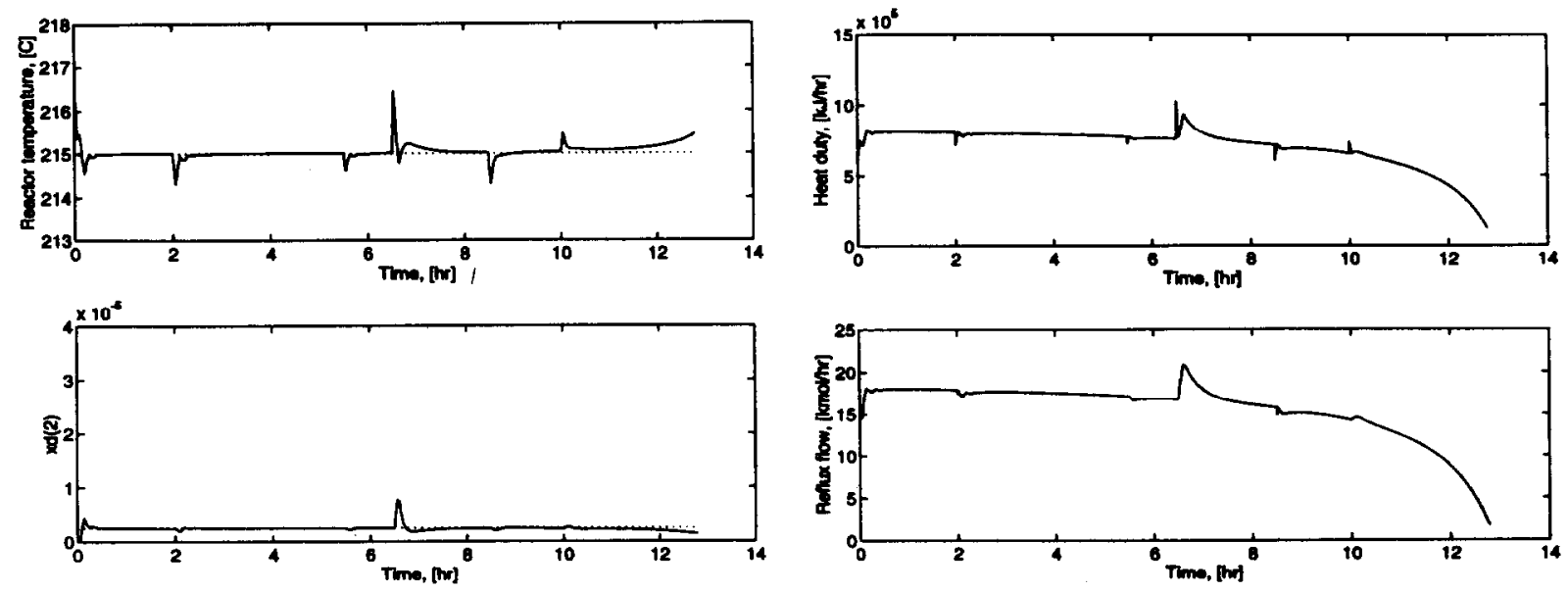

Figure 18 Two-point control with disturbances in $Q_{\mathrm{R}}$. Reactor temperature, distillate composition, heat input and reflux flow with set-points $T_{\mathrm{N}}^{\mathrm{sel}}=$ $215^{\circ} \mathrm{C}$ and $x_{\mathrm{D} .2}=2.5 \times 10^{-6}$. (Dotted lines: set-points)

- one-point bottom control (controlling the reactor temperature directly),

- two-point control (controlling both the distillate composition and the reactor temperature),

- one-point column control (controlling the temperature on a tray in the column).

It was found that with the one-point bottom strategy good control of the reactor temperature was achieved if the set-point temperature was specified below a maximum value. This is illustrated in Figure 17 for the case with disturbances in reboiler heat duty. The disturbances are the same as in Figure 3. The maximum reactor temperature is, however, difficult to estimate a priori and in practice the set-point must be specified low enough to ensure an acceptable performance. This will of course result in a slower reaction and a longer batch time.

Two-point control allows both the reactor temperature and the distillate composition to be controlled.
Energy will be saved compared with one-point control as the heat duty can be reduced. Two-point control of the process including the disturbances in reboiler heat duty is given in Figure 18. Also in this case good control is achieved but both the reactor temperature and the distillate composition deviate from their set-points towards the end of the batch due to the interactions between the control loops.

The existing operating practice, controlling the temperature at the top of the column, is poor, sensitive to noise and leads to a varying loss of reactant $R_{2}$ and thereby varying product quality. The measuring point should therefore be moved from the top tray and further down in the column. The proposed new strategy of onepoint column control, where the temperature on tray 5 is controlled, has several advantages:

- no loss of reactant $\mathbf{R}_{2}$ (compared to controlling the top temperature), 

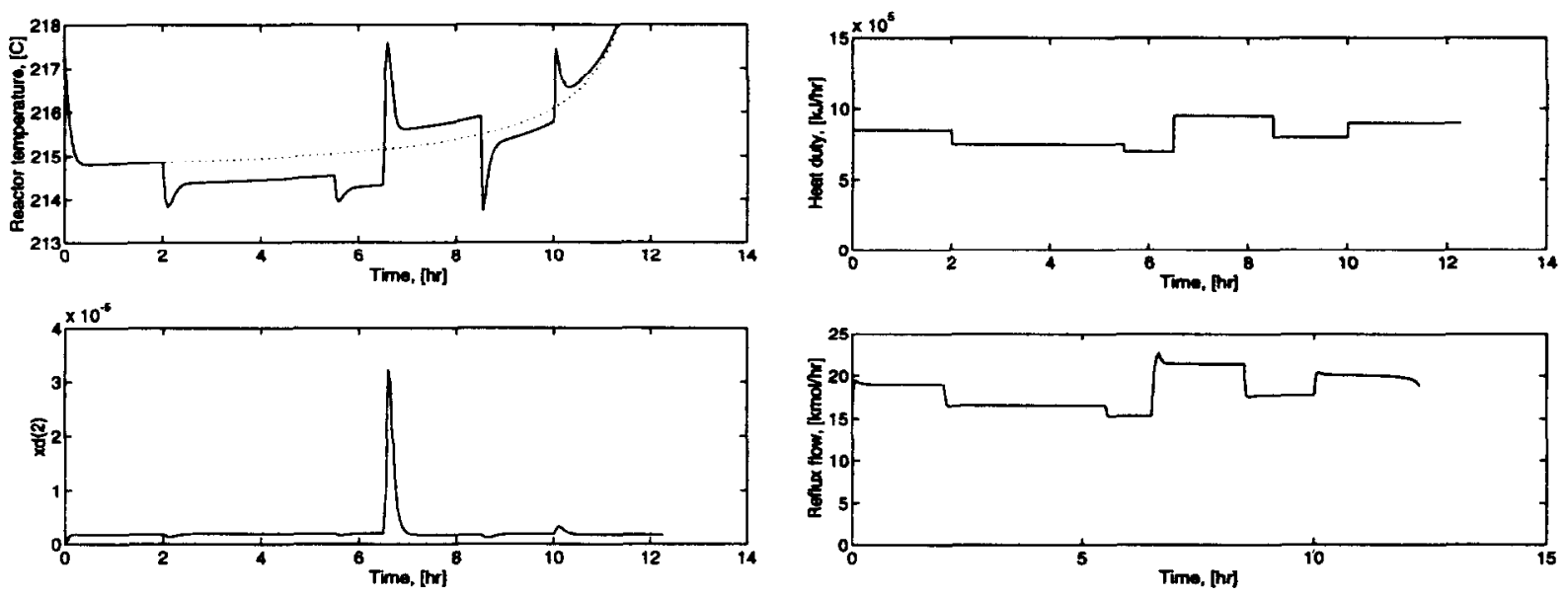

Figure 19 One-point column control with disturbances in $Q_{R}$. Reactor temperature, distillate composition, heat input and reflux flow $\left(u_{1}\right)$ with setpoint $T_{s}^{\text {set }}=170^{\circ} \mathrm{C}$. (Dotted line: undisturbed case)

- need not worry about maximum attainable reactor temperature (compared to controlling the reactor temperature directly by one-point bottom control),

- no interactions with other control loops (compared to two point control).

The temperature profile for one-point column control with disturbances in the system is given in Figure 19. It can be seen that also with this control strategy the deviations in the reactor temperature are small compared with the open-loop strategy in Figure 3. The deviations are, however, larger than for one-point bottom or twopoint control, but if the reactor temperature can be allowed to deviate about $\pm 0.5^{\circ} \mathrm{C}$ then one-point column control is the simplest and most efficient control strategy.

\section{Conclusions}

In this paper a combined batch reactor/distillation process has been presented. The need for feedback control for reactive batch distillation has been discussed and it has been shown that the same amount of light product formed should be removed in the separation as the amount being formed by the reaction at any time.

A linearized model has been found to describe the process behaviour satisfactorily for central analysis purposes. The effect of operating point and of disturbances has been discussed based on the linearized model. It has been found that the system's response to changes varies with time as the conditions in the column/reactor change. Also the responses are generally non-linear.

Different control strategies have been presented. The one-point column control strategy is simple and was found to give good control of the process also in the presence of disturbances.

\section{References}

1 Sørensen, E. and Skogestad, S. AIChE 1991 Annual Meeting, Los Angeles, paper 140e, 1991

2 Sørensen, E. and Skogestad, S. presented at NATO Advanced Study Institute, Batch Processing Systems Engineering, Antalya, Turkey, May-June 1992
3 Roat, S.D., Downs, J.J., Vogel, E.F. and Doss, J.E. Presented at CPC'3 (1986)

4 Cuille, P.E. and Reklaitis, G.V. Comp. Chem. Eng. 1986, 10(4), 389

5 Reuter, E., Wozny, G. and Jeromin, L. Proc. CHEMDATA'88, Gothenburg, 1988, 322

6 Albet, J., Le Lann, J.M., Joulia, X. and Koehret, B. Proc. COPE'91, Barcelona, Spain, 1991, 75

7 Egly, H., Ruby, V. and Seid, B. Comp. Chem. Eng. 1979, 3, 169

8 Egly, H., Ruby, V. and Seid, B. Ger. Chem. Eng. 1983, 6, 220

9 Daubert, T.E. and Danner, R.P. 'Data Compilation Tables of Properties of Pure Compounds' Design Institute for Physical Property Data, AIChE, Hemishere Publishing, 1985

10 Sørensen Leversund, E., Macchietto, S., Stuart, G. and Skogestad, S. Comp. Chem. Eng. 1994, 18 Suppl., S391 (supplement from ESCAPE'3, Graz, July 1993)

11 Skogestad, S. and Morari, M. Ind. Eng. Chem. Res. 1988, 27(10), 1848

12 Skogestad, S. IFAC symposium DYCORD'92, Maryland, 1992

13 Wolff, E.A., Skogestad, S., Hovd, M. and Mathisen, K.W. presented at the IFAC Workshop on Interactions Between Process Design and Control, Imperial College, London, September 6-8, 1992

\section{Nomenclature}

\begin{tabular}{|c|c|}
\hline$A$ & system matrix \\
\hline$B$ & system matrix \\
\hline$C$ & system matrix \\
\hline$c_{i}$ & concentration of component $i$ in reactor $\left(\mathrm{kmol} \mathrm{m}^{-3}\right)$ \\
\hline$D$ & system matrix \\
\hline d & disturbance vector \\
\hline$E_{t}$ & activity coefficient for reaction $i\left(\mathrm{~kJ} \mathrm{~mol}^{-1}\right)$ \\
\hline$E$ & system matrix \\
\hline$F$ & system matrix \\
\hline$G(s)$ & transfer function \\
\hline$G_{\mathrm{d}}(s)$ & transfer function for disturbances \\
\hline$h^{\mathbf{L}_{j}}$ & liquid enthalpy $\left(\mathrm{kJ} \mathrm{kmol}^{-1}\right)$ \\
\hline$h_{\mathrm{j}}{ }^{\mathrm{J}}$ & vapour enthalpy $\left(\mathrm{kJ} \mathrm{kmol}^{-1}\right)$ \\
\hline$H_{A}$ & liquid holdup in the accumulator $(\mathrm{kmol})$ \\
\hline$H_{\mathrm{j}}$ & liquid holdup on the trays $(\mathrm{kmol})$ \\
\hline$H_{\mathrm{j}}^{0}$ & initial liquid holdup on the trays $(\mathrm{kmol}(=0.1 \mathrm{kmol}))$ \\
\hline$H_{\mathrm{N}}$ & liquid holdup in the reactor ( $\mathrm{kmol}$ ) \\
\hline$H_{\mathrm{C}}$ & liquid holdup in the condenser ( $\mathrm{kmol})$ \\
\hline$k_{0 i}$ & frequency factor for reaction $i$ \\
\hline$K_{\mathrm{p}}$ & controller gain \\
\hline$L$ & reflux flow $\left(\mathrm{kmol} \mathrm{h}^{-1}\right)$ \\
\hline$L_{i}$ & internal liquid flow $\left(\mathrm{kmol} \mathrm{h}^{-1}\right)$ \\
\hline$L^{0}$ & initial liquid flow $\left(\mathrm{kmol} \mathrm{h}^{-1}\left(=15 \mathrm{kmol} \mathrm{h}^{-1}\right)\right)$ \\
\hline$L_{\mathrm{D}}$ & distillate flow $\left(\mathrm{kmol} \mathrm{h}^{-1}\right)$ \\
\hline$N$ & number of theoretical stages \\
\hline$n_{\mathrm{c}}$ & number of components \\
\hline $\boldsymbol{P}_{i}$ & pressure (atm) \\
\hline$P_{j}^{\text {vap }}$ & vapour pressure (atm) \\
\hline$Q_{\mathrm{c}}$ & condenser heat duty $\left(\mathrm{kJ} \mathrm{h}^{-1}\right)$ \\
\hline$Q_{\kappa}$ & reboiler heat duty $\left(\mathrm{kJ} \mathrm{h}^{-1}\right)$ \\
\hline
\end{tabular}




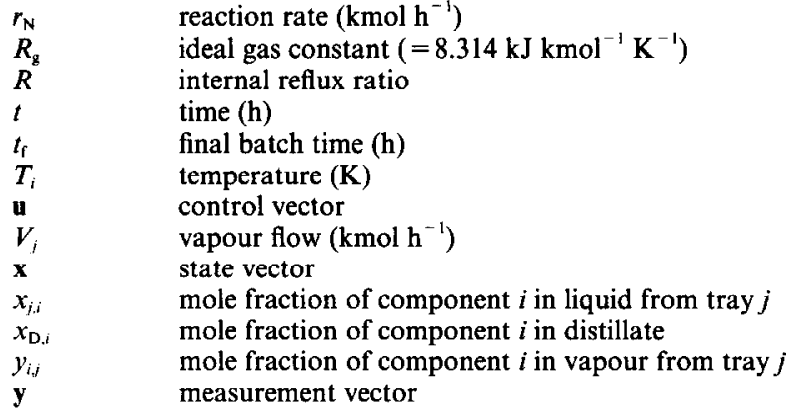

\section{Greek letters}

$\begin{array}{ll}\alpha_{i} & \text { relative volatility } \\ \Delta & \text { deviation from operating point } \\ \tau & \text { hydraulic time constant }\left(\mathrm{h}^{-1}\right) \\ \tau_{1} & \text { integral time for controller }(\mathrm{h}) \\ \xi_{j} & \text { stoichiometric coefficient } \\ \rho_{i} & \text { liquid density of component } i\left(\mathrm{kmol} \mathrm{m}^{-3}\right)\end{array}$

Subscripts and superscripts

$\begin{array}{ll}i & \text { component number } \\ j & \text { tray number } \\ \text { set } & \text { set point } \\ * & \text { nominal value }\end{array}$

\section{Appendix. Dynamic model of reactive batch distillation column}

The equations used in this study describing the dynamic behaviour of the combined batch reactor/batch distillation column consist of the total mass balance, the mass balance for each component, the energy balance, tray hydraulics and phase equilibrium and are valid under the following assumptions:

Al A staged model is used for the distillation column.

A2 Perfect mixing and equilibrium between vapour and liquid on all stages is assumed.

A3 The vapour phase holdup is negligible compared to the liquid phase holdup.

A4 The stage pressures and the plate efficiencies are constant.

A5 Changes in liquid enthalpies are neglected $\left(\mathrm{d} h^{\mathrm{L}} /\right.$ $\mathrm{d} t \approx 0$ ). This yields an algebraic energy balance.

A6 Linear tray hydraulics is considered.

A7 Total condensation with no subcooling in the condenser is assumed.

A8 The chemical reaction is limited to the reactor.

$A 9$ Raoult's law for the vapour-liquid equilibrium holds.

A10 The condenser holdup is assumed to be perfectly controlled.

A11 Immediate heat input is assumed.

Below $j$ denotes the stage number and $i$ the component number. The following differential and algebraic equations result.

reboiler, $i=1, n_{\mathrm{c}}, j=N$ :

$$
\begin{aligned}
& \mathrm{d} H_{N} / \mathrm{d} t=L_{N-1}-V_{N}+\sum_{i=1}^{n_{\mathrm{c}}} \xi_{i} r_{N} \\
& \mathrm{~d}\left(H_{N} x_{N i}\right) / \mathrm{d} t=L_{N-1} x_{N-1, i}-V_{N} y_{N i}+\xi_{i} r_{N} \\
& 0=L_{N-1}\left(h_{N-1}^{\mathrm{L}}-h_{N}^{\mathrm{L}}\right)-V_{N}\left(h_{N}^{\mathrm{v}}-h_{N}^{\mathrm{L}}\right)+Q_{R} \\
& r_{N}=r_{N}\left(c_{i}, T_{N}\right) \\
& c_{i}=\frac{x_{N i} H_{N}}{\sum_{i=1}^{n_{\mathrm{c}}} x_{N i} H_{N} / \rho_{i}}
\end{aligned}
$$

column tray, $i=1, n_{\mathrm{c}}, j=1, N-1$ :

$$
\begin{aligned}
& \mathrm{d} H_{j} / \mathrm{d} t=L_{j-1}+V_{j+1}-L_{j}-V_{j} \\
& \mathrm{~d}\left(H_{j} x_{j i}\right) / \mathrm{d} t=L_{j-1} x_{j-1, i}+V_{j+1} y_{j+1, i}-L_{j} x_{j i}-V_{j} y_{j i} \\
& 0=L_{j-1}\left(h_{j-1}^{\mathrm{L}}-h_{j}^{\mathrm{L}}\right)+V_{j+1}\left(h_{j+1}^{\mathrm{V}}-h_{j}^{\mathrm{L}}\right)-V_{j}\left(h_{j}^{\mathrm{V}}-h_{j}^{\mathrm{L}}\right)
\end{aligned}
$$

$$
\begin{aligned}
& \text { condenser, } i=1, n_{\mathrm{c}}: \\
& \begin{array}{l}
0=V_{1}-L-L_{\mathrm{D}} \\
H_{\mathrm{C}} \cdot \mathrm{d}\left(x_{\mathrm{D}, i}\right) / \mathrm{d} t=V_{1} y_{1, i}-L x_{\mathrm{D}, i}-L_{\mathrm{D}} x_{\mathrm{D}, i} \\
0=V_{1} h_{1}^{\mathrm{V}}-L h_{\mathrm{C}}^{\mathrm{L}}-L_{\mathrm{D}} h_{\mathrm{C}}^{\mathrm{L}}-Q_{\mathrm{C}} \\
L=R \cdot V_{1}
\end{array}
\end{aligned}
$$

accumulator, $i=1, n_{\mathrm{c}}$ :

$$
\begin{aligned}
& \mathrm{d} H_{\mathrm{A}} / \mathrm{d} t=L_{\mathrm{D}} \\
& \mathrm{d}\left(H_{\mathrm{A}} x_{\mathrm{A} i}\right) / \mathrm{d} t=L_{\mathrm{D}} x_{\mathrm{D} i}
\end{aligned}
$$

linearized tray hydraulics, $j=1, N-1$ :

$$
L_{j}=L_{j}^{0}+\frac{H_{i}-H_{i}^{0}}{\tau}
$$

equilibrium, $i=1, n_{\mathrm{c}}, j=1, N$ :

$$
y_{i i}=k_{i i} x_{i i}
$$

restriction, $i=1, n_{\mathrm{c}}, j=1, N$ :

$$
\sum_{i=1}^{n_{c}} y_{j i}=1
$$

physical properties, $i=1, n_{\mathrm{c}}, j=1, N$ :

$$
\begin{aligned}
& k_{j i}-\frac{P_{j i}^{\mathrm{vap}}\left(T_{j}\right)}{P} \\
& h_{j}^{\mathrm{L}}=h_{j}^{\mathrm{L}}\left(x_{j i}, T_{j}\right) \\
& h_{j}^{\mathrm{V}}=h_{j}^{\mathrm{V}}\left(y_{j i}, T_{j}\right) \\
& \rho_{i}=\rho_{i}(T)
\end{aligned}
$$

The solid polymer product forms a separate phase and is therefore not included in the model. The initial conditions are total reflux and no reaction. Note that the reflux ratio is given as the internal reflux ratio $L / V_{1}$ since this is better solved numerically (between 0 and 1 instead of 0 and $\infty$ ). 